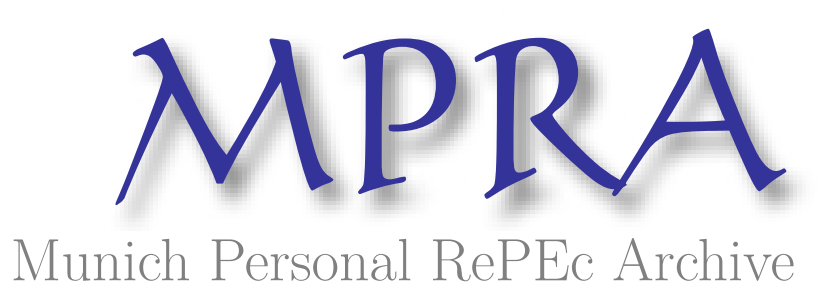

\title{
The Currency Equivalent Index and the Current Stock of Money
}

Kelly, Logan J

Bryant University

15 February 2008

Online at https://mpra.ub.uni-muenchen.de/7176/

MPRA Paper No. 7176, posted 15 Feb 2008 19:22 UTC 


\title{
The Currency Equivalent Index and the Current Stock of Money
}

\author{
Logan J. Kelly \\ Bryant University, Department of Economics, Smithfield, RI 02917 \\ e-mail: lkelly@bryant.edu Ph: (401)232-6897 Fax: (401) 232-6319
}

\begin{abstract}
The currency equivalent index provides an elegant method for measuring the stock of money, but it rests upon assumptions that do not match an important characteristic of the data. Thus, it is unclear what, if anything, the CE measures. This paper attempts to answer this question by deriving the current stock of money (CSM), which is defined to be the discounted present value of the monetary service flows provided by only the current portfolio of monetary assets, and then analyzing the assumptions under which the current stock of money can be measured by the currency equivalent index.
\end{abstract}

Key words: Currency Equilivant Index, Monetary Aggregation, Money Stock JEL classification codes: E49

\section{Introduction}

The currency equivalent index (CE), first proposed by Hutt (1963), was formally derived by Rotemberg, Driscoll, and Poterba (1995). The CE was intended to be a competitor of the Divisia flow index, but the CE index is inferior to the Divisia index because it is only a valid measure of the monetary service flow under the more restrictive assumption that the representative agent's utility function was blockwise strongly separable in currency. However, Barnett (1991) showed that the CE could be interpreted as the discounted economic stock of money (ESM) by assuming only blockwise weak separability, but only if total expenditure on monetary services follows a martingale process.

The currency equivalent index (CE) provides a simple method for measuring the ESM, but it rests upon assumptions that do not match an important 
characteristic of the data (see Barnett, Keating, and Kelly, 2008). Specifically, Barnett (1991) assumed that total nominal expenditure on monetary services (TE) follows a martingale process. Barnett et al. (2008) showed that TE much more closely follows a martingale with drift process. Thus, it is unclear what, if anything, the CE measures. This paper attempts to answer this question by deriving the current stock of money (CSM), which is defined to be the discounted present value of the monetary service flows provided by only the current portfolio of monetary assets, and then analyzing the assumptions under which the current stock of money can be measured by the currency equivalent index. The CSM differs from Barnett's (1991) economic stock of money (ESM) in that it ignores future monetary portfolio decisions of the representative agent.

To calculate the CSM, the current and expected future service flows provided by a single unit of each monetary asset is needed, thus, the user cost of each monetary asset must be forecasted individually. Three forecasting models: martingale forecasts, auto regression forecasts and targeted factor model forecasts are evaluated. I found that the martingale forecast preformed best at all levels of aggregation and at all time horizons, and I will show that if martingale expectations are assumed, then the current stock of money reduces to the currency equivalent index. While Barnett, Chae, and Keating (2005) found that assuming martingale expectation causes the CE to be a downward biased measurment of the ESM, I argue that because the CSM ignores future monetary portfolio decisions, the CE is an unbiased measure the CSM.

The remainder of this paper is organized as follows. Section two defines the CSM and derives the link between the CSM and the CE. Section three compares the validity of martingale expectations to that of more sophisticated forecasting models. Section four compares the CE to the CSM calculated under perfect foresight, and Section five concludes.

\section{The Current Stock of Money}

\subsection{Derivation under Perfect Foresight}

Barnett (1991) defines the economic stock of money, $V_{t}$, as

$$
V_{t} \equiv \sum_{s=t}^{T} \sum_{n=1}^{N}\left[\frac{p_{s}^{*}}{\rho_{s}}-\frac{p_{s}^{*}\left(1+r_{n, s}\right)}{\rho_{s+1}}\right] m_{n s}
$$


where the discount rate for period $s$ is

$$
\rho_{s}=\left\{\begin{array}{ll}
1 & s=t \\
\prod_{u=t}^{s-1}\left(1+R_{u}\right) & s>t
\end{array},\right.
$$

$R_{s}$ is the benchmark rate, i.e. rate of return provided by a pure investment asset, at time period $s, r_{n, s}$ is the user cost of monetary asset $m$ at time period $s, m_{n, s}$ is the quantity of monetary asset $m$ at held time period $s$, and $p_{s}^{*}$ is the true cost of living index. As can be seen from (1), the economic stock of money takes into consideration the current and future monetary portfolio decisions of the representative agent.

Now define the CSM, $V_{t}^{\prime}$, to be

$$
V_{t}^{\prime} \equiv \sum_{s=t}^{\infty} \sum_{n=1}^{N}\left[\frac{p_{s}^{*}}{\rho_{s}}-\frac{p_{s}^{*}\left(1+r_{n, s}\right)}{\rho_{s+1}}\right] m_{n t}
$$

This definition follows from (1), in that it is the portion of the Fisherine wealth constraint directly attributable to the current monetary portfolio. To see this, define

$$
\tilde{m}_{n, t+j}=\left\{\begin{array}{ll}
0 & \text { if } j=0 \\
\sum_{i=1}^{j} \Delta m_{n, t+i} & \text { if } j>0
\end{array},\right.
$$

and note that

$$
m_{n s}=m_{n t}+\tilde{m}_{n s} \forall s \geq t .
$$

Substituting (5) into (1) yields

$$
\begin{aligned}
V_{t} & =\sum_{s=t}^{\infty} \sum_{n=1}^{N}\left[\frac{p_{s}^{*}}{\rho_{s}}-\frac{p_{s}^{*}\left(1+r_{n, s}\right)}{\rho_{s+1}}\right]\left(m_{n t}+\tilde{m}_{n s}\right) \\
& =\sum_{s=t}^{\infty} \sum_{n=1}^{N}\left[\frac{p_{s}^{*}}{\rho_{s}}-\frac{p_{s}^{*}\left(1+r_{n, s}\right)}{\rho_{s+1}}\right] m_{n t}+\sum_{s=t}^{\infty} \sum_{n=1}^{N}\left[\frac{p_{s}^{*}}{\rho_{s}}-\frac{p_{s}^{*}\left(1+r_{n, s}\right)}{\rho_{s+1}}\right] \tilde{m}_{n s},
\end{aligned}
$$

where the first double summation is the current stock of money. Thus, I can define the simple sum stock of monetary assets to be the sum of three stock variables: one, the current stock of money, two, the present value of monetary service flows resulting from future monetary portfolio decisions, and three, the non-monetary stock.

Substituting (2) into (3) yields

$$
V_{t}^{\prime}=\sum_{n=1}^{N}\left\{\sum_{s=t}^{\infty}\left[\frac{p_{s}^{*}\left(R_{s}-r_{n s}\right)}{\prod_{u=t}^{s}\left(1+R_{s}\right)}\right] m_{n t}\right\}
$$


Equation (6) can be rewritten as

$$
V_{t}^{\prime}=\sum_{n=1}^{N}\left(m_{n t} \sum_{s=t}^{\infty} \frac{\psi_{n s}}{\rho_{s}}\right)
$$

where $\sum_{s=t}^{\infty} \frac{\psi_{n s}}{\rho_{s}}$ is the present value of the nominal monetary service flow provided by one unit on monetary asset $n$.

\subsection{Extension to Uncertainty}

Barnett (1995) and Barnett, Liu, and Jensen (1997) showed that assuming inter-temporal strong separability and risk neutrality, all the results on user cost and Divisia aggregation can be extended to the case of uncertainty by replacing all random variables with their expectations. Following Barnett et al. (2008) and Barnett et al. (2005), who apply the consumption-based capital asset pricing model theory, the formulas for the economic capital stock of money becomes

$$
V_{t}=E_{t}\left[\sum_{s=t}^{\infty}\left(\Gamma_{s} \sum_{n=1}^{N} m_{n s} \psi_{n s}\right)\right]
$$

where

$$
\Gamma_{s}=\beta^{s-t} \frac{\partial u}{\partial C_{s}} / \frac{\partial u}{\partial C_{t}}
$$

is the subjectively-discounted marginal rate of inter-temporal substitution be-

tween consumption in the current period $t$ and the future period $s .{ }^{1}$ Substituting (5) into (8) yields

$$
V_{t}=E_{t}\left(\sum_{s=t}^{\infty} \Gamma_{s} \sum_{n=1}^{N} m_{n t} \psi_{n s}\right)+E_{t}\left(\sum_{s=t}^{\infty} \Gamma_{s} \sum_{n=1}^{N} \tilde{m}_{n s} \psi_{n s}\right)
$$

where the first double summation is the current stock of money. Thus, the CSM, $V_{t}^{\prime}$, can be defined under risk as

$$
V_{t}^{\prime}=E_{t}\left(\sum_{s=t}^{\infty} \Gamma_{s} \sum_{n=1}^{N} m_{n t} \psi_{n s}\right)
$$

\footnotetext{
1 See Blanchard and Fischer (1989) section 6.3 and Cochrane (2005).
} 


\subsection{Linking the CSM to the CE}

I begin by assuming that the expectation of the stochastic discount factor in time period $t$ is

$$
E_{t}\left(\Gamma_{s}\right)=\prod_{u=t}^{s}\left[1+E_{t}\left(R_{u}\right)\right]^{-1}
$$

Then (11) becomes

$$
V_{t}^{\prime}=\sum_{s=t}^{\infty} \frac{E_{t}\left(\sum_{n=1}^{N} m_{n t} \psi_{n s}\right)}{\prod_{u=t}^{s}\left[1+E_{t}\left(R_{u}\right)\right]}+\operatorname{cov}\left(\sum_{n=1}^{N} m_{n t} \psi_{n s}, \Gamma\right)
$$

Now assume that the benchmark rate follows a martingale process, so that $E_{t}\left(R_{s}\right)=R_{t}$ for all $s \geq t$, and that $\operatorname{cov}\left(\sum_{n=1}^{N} m_{n t} \psi_{n s}, \Gamma\right)=0$. Then

$$
V_{t}^{\prime}=\sum_{s=t}^{\infty} \frac{\sum_{n=1}^{N}\left[m_{n t} E_{t}\left(\psi_{n s}\right)\right]}{\left(1+R_{t}\right)^{s-t}}
$$

Finally, assume that $\psi_{n s}$ also follows a martingale process $\forall n=1 \ldots N$, then (13) can be rewritten as

$$
V_{t}^{\prime}=\sum_{s=t}^{\infty} \sum_{n=1}^{N}\left[\frac{R_{t}-r_{n t}}{\left(1+R_{t}\right)^{s-t+1}}\right] m_{n t}=\sum_{n=1}^{N} \frac{R_{t}-r_{n t}}{R_{t}} m_{n t},
$$

where the right hand side of (14) is the currency equivalent index.

\section{Evaluating Martingale Expectations}

As was seen in the previous section, the CSM reduces to the CE if the rate of return on the benchmark asset and the user costs of each monetary asset follow a martingale process. In this section, I will evaluate the validity of using a martingale forecasting model to generate the expectations needed to calculate the CSM. Martingale forecasts will be compared to targeted factor model (TFM) and auto regressive (AR) forecasts at the 6 month, 12 month, 24 month and 36 month time horizons.

\subsection{Data Description}

In this paper, I will look at monthly data from 1960:03 - 2006:02 that was collected from Economic Data - FRED ${ }^{\mathrm{R}}$ database maintained by the Saint 


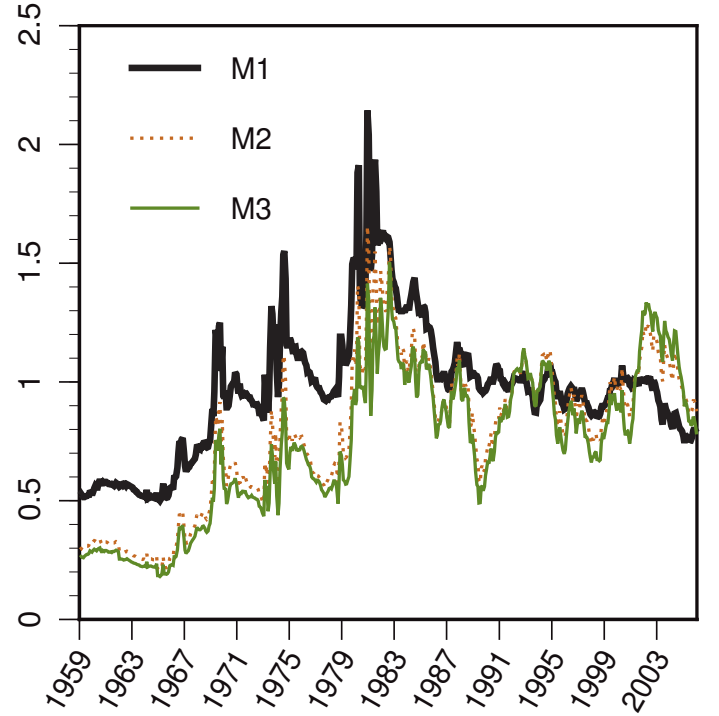

Figure 1. Aggregate User Cost of Money (1959:01 - 2006:02)

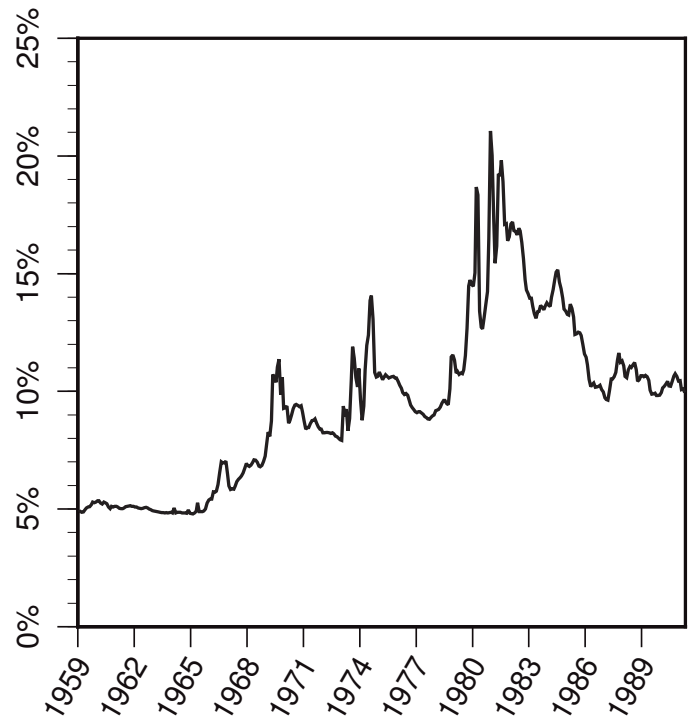

Figure 2. Return Yielded by the Benchmark Asset (1959:01 - 2006:02)

Louis Federal Reserve ${ }^{2}$ and the United States Bureau of Labor Statistics. ${ }^{3}$ The variables to be forecasted are the aggregate user costs of money at the M1, M2 and M3 levels of aggregation and the return yielded by the benchmark asset. Figure 1 plots the aggregate user cost of money at the M1, M2 and M3 levels of aggregation. Figure 2 plots the return yielded by the benchmark asset. I test each variable for stationarity using the Augmented Dickey-Fuller test and the Dickey-Fuller GLS test (Elliott, Rothenberg, and Stock, 1996). Each variable is found to be $\mathrm{I}(1)$ non-stationary, and so each is differenced once.

The panel of explanatory variables includes 112 series including selected longterm and short-term interest rates, unemployment data, aggregate price data, monetary aggregate data and other macroeconomic time series data. Each variable is tested for stationarity using the Augmented Dickey-Fuller test and the Dickey-Fuller GLS (Elliott et al., 1996). Each variable is transformed by taking logs, first or second differences as needed.

$\overline{2}$ Saint Louis Federal Reserve: 2006, Economic Data - FRED ${ }^{\circledR}$. http://research.stlouisfed.org/fred2/

3 United States Bureau of Labor Statistics: 2006. http://www.bls.gov 


\subsection{Forecasting Methodology}

\subsubsection{Martingale Model}

The martingale forecast model is the main model for evaluation in this study because martingale expectations are necessary to justify the use of the CE. The use of martingale forecasting is supported by the fact that the user costs of monetary assets and the benchmark rate are functions of, and highly correlated to, interest rates. There is a long tradition of modeling interest rates as martingale processes. Arguments supporting martingale expectations date back to Sargent (1976) and Pesando (1979). Elliott and Baier (1979) found empirical evidence for the use of martingale forecasts of interest rates. I will use the forecasting equation

$$
\hat{y}_{T+h \mid T}^{h}=y_{T},
$$

and I will refer to this model as martingale in all following tables and figures.

\subsubsection{Auto-regressive Model}

The first comparison model I will use is a simple auto-regressive process of $p$ lags using the Bayesian information criterion to select $p$. An $\mathrm{AR}(\mathrm{p})$ model is selected as a model for comparison because of its long standing usefulness in forecasting of all types. In many instances, the $\mathrm{AR}(\mathrm{p})$ model has been shown to outperform much more complicated models. Thus, the $\mathrm{AR}(\mathrm{p})$ is a natural benchmark for comparing the performance of any forecasting methodology. I will refer to this model as AR in all following tables and figures, and I will use the forecasting equation

$$
\hat{y}_{T+h \mid T}^{h}=c+\sum_{i=0}^{p-1} \beta_{i} y_{t-i} .
$$

\subsubsection{Targeted Factor Model}

Let $X_{(T \times N)}$ be a matrix of $N$ observed variables over $T$ periods. Then consider the model suggested by Bai and Ng (2002),

$$
X=F \Lambda^{\prime}+e,
$$

where $\Lambda=\left(\lambda_{1} \ldots \lambda_{N}\right)^{\prime}$ is a $(N \times r)$ matrix of loading factors, $F$ is a $(T \times r)$ matrix of common factors, and $e$ is a $(T \times N)$ matrix of idiosyncratic errors. See Bai and $\mathrm{Ng}$ (2002) for the necessary assumptions for consistent estimation of the $r$ common factors. The factors are estimated by the method of asymptotic principle components. 
In order to estimate the number of common factors, $r$, minimize, by choosing $k$, the following information criterion:

$$
I C_{p 1}(k)=\ln \left[V\left(k, \hat{F}^{k}\right)\right]+k\left(\frac{N+T}{N T}\right) \ln \left(\frac{N T}{N+T}\right)
$$

where $\hat{F}^{k}$ equals $\sqrt{T}$ times the eigenvectors corresponding to the $k$ largest eigenvalues of the $(T \times T)$ matrix $X X^{\prime}$ and

$$
V\left(k, \hat{F}^{k}\right)=\min _{\Lambda}\left[(N T)^{-1} \sum_{i=1}^{N} \sum_{t=1}^{T}\left(X_{i t}-\lambda_{i}^{k^{\prime}} F_{t}^{k}\right)\right] .
$$

One limitation of the method of principle components is that it presupposes a linear linking function between the data and the latent factors. Bai and $\mathrm{Ng}$ (2007) propose a more flexible approach that allows for rudimentary nonlinearity in the factor linking function. Define $X^{*}$ to be $X$ augmented by a subset of the unique cross-products of $X$. Specifically, consider $X^{*}=\left\{X_{t n}, X_{t n}^{2}\right\}$, which Bai and $\mathrm{Ng}$ referred to as squared principle components (SPC).

Boivin and $\mathrm{Ng}$ (2006) found that adding additional predictors that bear little information about factor components does not necessarily improve forecasts. They found that when the data panel is too noisy, it is better to eliminate some of the data. The optimal panel of predictors could be determined by the use of an information criteria, such as BIC. However, with $N$ possible predictors, there are $2^{N}$ possible sets to consider. Hence, this method is impractical. Bai and Ng examine the use the method of least angle regression (LARS) developed by Efron et al. (2004) to target the panel. I use this method in conjunction with SPC to estimate a targeted factor model.

I use the forecasting equation suggested by Bai and $\mathrm{Ng}$ (2007),

$$
\hat{y}_{T+h \mid T}^{h}=\hat{\alpha}^{\prime} W_{T}+\hat{\beta}^{\prime} \hat{F}_{T}^{k}
$$

where $\hat{y}_{T+h}^{h}$ is the $h$-period forecast of the variable $y_{t}$ given the information available as of time period $T, W_{T}$ is a vector of predetermined variables that could include a constant and/or lags of $y_{t+h},{\hat{F_{T}}}^{k}$ is a vector of $k$ common factors of $X$, and the parameters $\alpha$ and $\beta$ are obtained from the ordinary least squares estimation of

$$
y_{t+h}^{h}=\alpha^{\prime} W_{T}+\beta^{\prime} \hat{F}_{T}^{k}+\varepsilon_{t+h} .
$$




\subsection{Criterion for Evaluation of Forecasting Performance}

To evaluate the forecasting performance of each model, we calculate root mean squared error and Theil's $U$ statistic. Let $y_{t+h}$ be the observed value of $y$ in period $t+h$, and let $\hat{y}_{t+h \mid t}$ be the $h$-period ahead forecast of $y$ conditional on information available in period $t$. Then

$$
R M S E_{H}(\text { model })=\sqrt{\frac{1}{H} \sum_{t=1}^{H}\left(y_{t+h}-\hat{y}_{t+h \mid t}\right)^{2}}
$$

and

$$
U_{H}(\text { model })=\frac{\sqrt{\frac{1}{H} \sum_{t=1}^{H}\left(y_{t+h}-\hat{y}_{t+h \mid t}\right)^{2}}}{\sqrt{\frac{1}{H} \sum_{t=1}^{H}\left(y_{t+h}-y_{t}\right)^{2}}}
$$

are calculated, where $h$ is the forecasting horizon and $H$ is the total number of forecasts. Theil's $U$ statistic compares a model's forecasting performance to that of the no change model. When $U$ is less than one, the model forecast performs better than the no-change forecast. When $U$ is greater than one, the model performs more poorly than the no-change forecast.

\subsection{Out of Sample Simulation Methodology}

The aggregate user cost of money and the return yielded by the benchmark asset are iteratively forecasted by restricting the data set to a rolling window of 240 observations, i.e. in period $T$ we restrict the data set to periods $t \in$ $\{T-240, \ldots, T\}$ for all periods $T$ starting in period 1980:03 and ending in period 2002:02. Thus, each forecast is made using only data before the forecast period. For example, the 12 month forecast of $T E_{t+12}$ uses only data available in time period $t$. After removing unit roots from the data, the adjusted data set contains 540 observations. This procedure is implemented for each forecasting method.

\subsection{Forecasting Results}

I find that martingale forecasts of the aggregate user cost of money and the yield on the benchmark asset are, if not optimal, extremely hard to improve upon with more sophisticated models. This result is not surprising given that the user costs of monetary assets are functions of, and highly correlated with, interest rates. Table 1 reports the performance of each forecast by measuring the root mean squared error (RMSE) and Theil's $U$ statistic. 
Table 1

Forecasting Model Comparison Results

\begin{tabular}{|c|c|c|c|c|c|}
\hline \multirow[b]{2}{*}{ Variable } & \multirow[b]{2}{*}{ Method } & \multicolumn{2}{|c|}{$\begin{array}{c}6 \text { Month } \\
\text { Forecasting Horizon }\end{array}$} & \multicolumn{2}{|c|}{$\begin{array}{c}12 \text { Month } \\
\text { Forecasting Horizon }\end{array}$} \\
\hline & & $R M S E$ & U Stat. & $R M S E$ & U Stat. \\
\hline \multirow[t]{3}{*}{ Benchmark Rate } & Martingale & 0.013 & 1.00 & 0.017 & 1.00 \\
\hline & AR & 0.014 & 1.07 & 0.018 & 1.09 \\
\hline & TFM & 0.056 & 4.20 & 1.094 & 65.16 \\
\hline \multirow[t]{3}{*}{$\mathrm{UC}(\mathrm{M} 1)$} & Martingale & 0.117 & 1.00 & 0.145 & 1.00 \\
\hline & $\mathrm{AR}$ & 0.124 & 1.06 & 0.161 & 1.11 \\
\hline & TFM & 0.140 & 1.19 & 0.214 & 1.48 \\
\hline \multirow[t]{3}{*}{$\mathrm{UC}(\mathrm{M} 2)$} & Martingale & 0.142 & 1.00 & 0.185 & 1.00 \\
\hline & AR & 0.149 & 1.05 & 0.204 & 1.10 \\
\hline & TFM & 0.161 & 1.34 & 0.258 & 1.39 \\
\hline \multirow[t]{4}{*}{$\mathrm{UC}(\mathrm{M} 3)$} & Martingale & 0.142 & 1.00 & 0.196 & 1.00 \\
\hline & $\mathrm{AR}$ & 0.149 & 1.05 & 0.214 & 1.09 \\
\hline & TFM & 0.156 & 1.10 & 0.225 & 1.15 \\
\hline & & \multicolumn{2}{|c|}{$\begin{array}{l}24 \text { Month } \\
\text { Forecasting Horizon }\end{array}$} & \multicolumn{2}{|c|}{$\begin{array}{c}36 \text { Month } \\
\text { Forecasting Horizon }\end{array}$} \\
\hline Variable & Method & $R M S E$ & U Stat. & $R M S E$ & U Stat. \\
\hline \multirow[t]{3}{*}{ Benchmark Rate } & Martingale & 0.024 & 1.00 & 0.028 & 1.00 \\
\hline & $\mathrm{AR}$ & 0.027 & 1.13 & 0.034 & 1.20 \\
\hline & TFM & 531.69 & 22144.78 & 257518 & 9089843 \\
\hline \multirow[t]{3}{*}{$\mathrm{UC}(\mathrm{M} 1)$} & Martingale & 0.200 & 1.00 & .234 & 1.00 \\
\hline & $\mathrm{AR}$ & 0.241 & 1.20 & .303 & 1.29 \\
\hline & TFM & 1.951 & 9.73 & 29.80 & 127.39 \\
\hline \multirow[t]{3}{*}{$\mathrm{UC}(\mathrm{M} 2)$} & Martingale & 0.243 & 1.00 & 0.281 & 1.00 \\
\hline & $\mathrm{AR}$ & 0.291 & 1.20 & 0.371 & 1.32 \\
\hline & TFM & 3.292 & 13.58 & 45.005 & 160.24 \\
\hline \multirow[t]{3}{*}{$\mathrm{UC}(\mathrm{M} 3)$} & Martingale & 0.253 & 1.00 & 0.298 & 1.00 \\
\hline & $\mathrm{AR}$ & 0.300 & 1.18 & 0.390 & 1.31 \\
\hline & TFM & 0.517 & 2.04 & 6.111 & 20.51 \\
\hline
\end{tabular}




\section{Comparison of CE to Perfect Foresight CSM}

\subsection{Calculating the Current Stock of Money}

I calculate the CSM, (7):

$$
V_{t}^{\prime}=\sum_{n=1}^{N}\left(m_{n t} \sum_{s=t}^{\infty} \frac{\psi_{n s}}{\rho_{s}}\right)
$$

by assuming perfect foresight and thus use actual future data to compute (7). The perfect foresight CSM (CSM_PF) is not a feasible index number, since future data cannot be known ex ante, but as in Barnett et al. (2005) and Barnett et al. (2008), I use CSM_PF to evaluate the performance of the CE which is based on forecasted data.

In practice, (7) must be evaluated for a finite number of periods, $H$, so that (7) becomes

$$
V_{t}^{\prime}=\sum_{n=1}^{N}\left(m_{n t} \sum_{s=t}^{H_{n}} \frac{\psi_{n s}}{\rho_{s}}\right) .
$$

To determine $H_{n}$ needed to calculate the CSM index number, I choose the smallest $H_{n}$ that satisfies the stopping criterion

$$
\left|\frac{\sum_{s=t}^{H_{n}} \frac{\psi_{n s}}{\rho_{s}}-\sum_{s=t}^{H_{n}-1} \frac{\psi_{n s}}{\rho_{s}}}{\sum_{s=t}^{H_{n}-1} \frac{\psi_{n s}}{\rho_{s}}}\right|<10^{-4} \quad \forall n \in\{1,2, \ldots, N\} .
$$

\subsection{Results}

In order to evaluate how well the $\mathrm{CE}$ index is able to measure the current stock of money, I compare the CE index to the perfect foresight CSM (PF) described above. ${ }^{4}$ Figures 4,6 and 8 plot the $\mathrm{CE}$ index and the PF at the M1, M2 and M3 levels of aggregation. Figures 3, 5 and 7 shows the deviation of the $\mathrm{CE}$ Index from the $\mathrm{PF}$ as a percent of $\mathrm{PF}$. The $\mathrm{CE}$ index overstates the $\mathrm{PF}$ by an average of 0.05 percent, 0.93 percent and 0.96 percent at the M1, M2 and M3 levels of aggregation respectively. Thus, at the M1, M2 and M3 levels of aggregation, the CE measures the current stock of money with nearly zero systematic bias observed. Table 2 reports the performance of the $\mathrm{CE}$ index by measuring the mean percent error (MPE), mean absolute percent error (MAPE) and root mean squared error (RMSE) of the CE index relative to perfect foresight CSM.

$\overline{4}$ The results are generated using Ox version 4.00 (Doornik, 2006). See http://www.doornik.com for further information. 


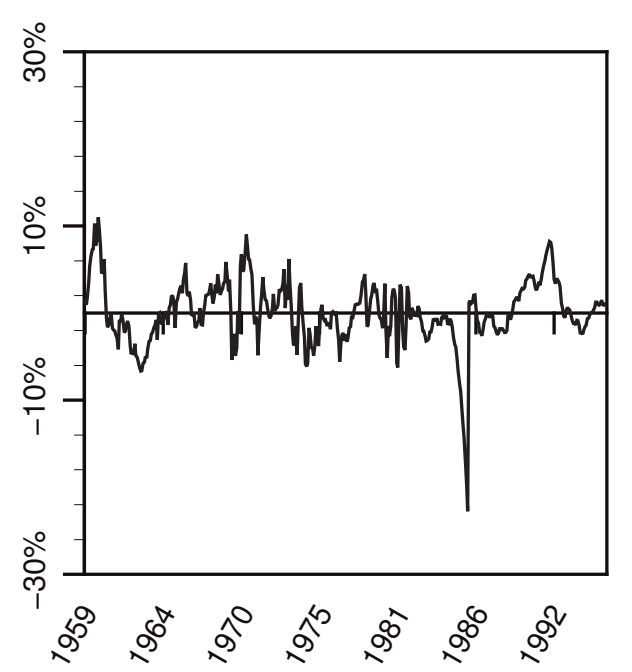

Figure 3. Percent Error of the MCE and the CE Relative to Perfect Foresight ESM (M1)

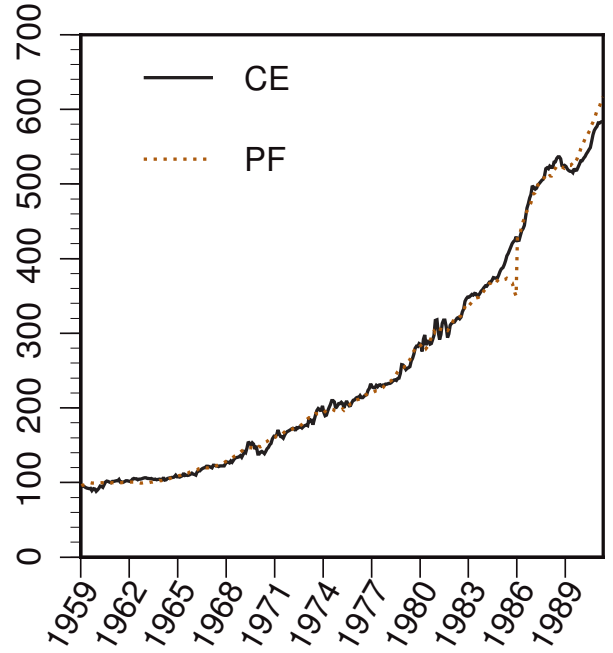

Figure 4. Current Capital Stock of Money (M1)

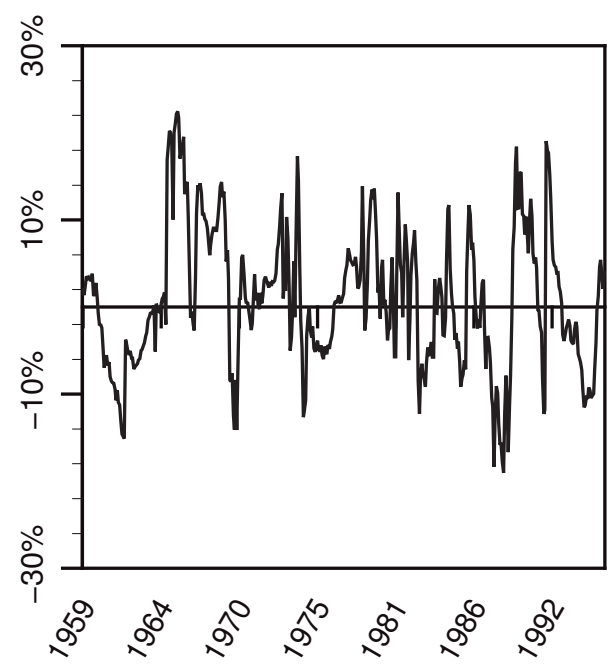

Figure 5. Percent Error of the MCE and the CE Relative to Perfect Foresight ESM (M2)

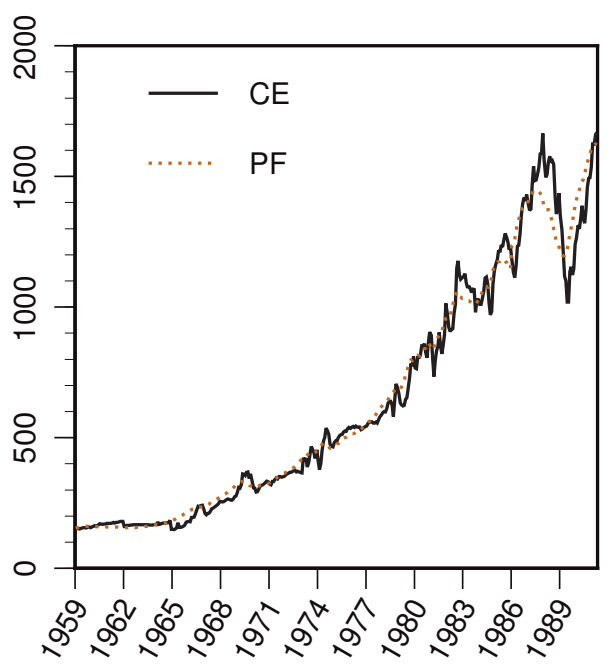

Figure 6. Current Capital Stock of Money (M2) 


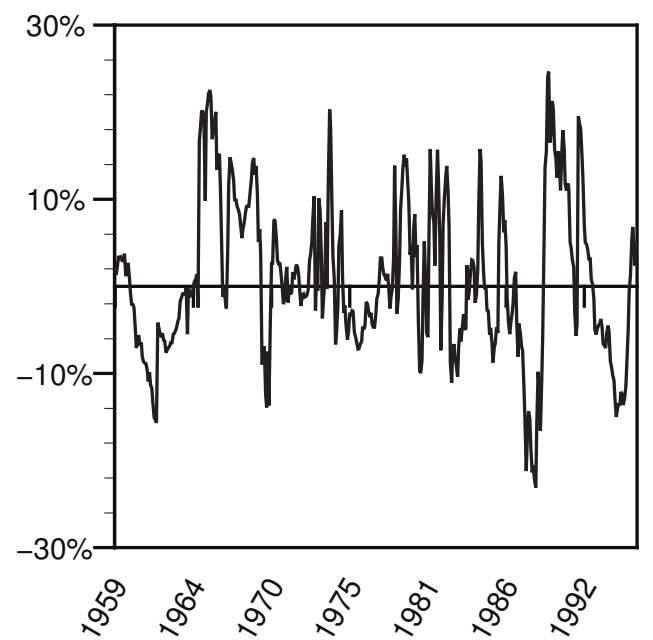

Figure 7. Percent Error of the MCE and the CE Relative to Perfect Foresight ESM (M3)

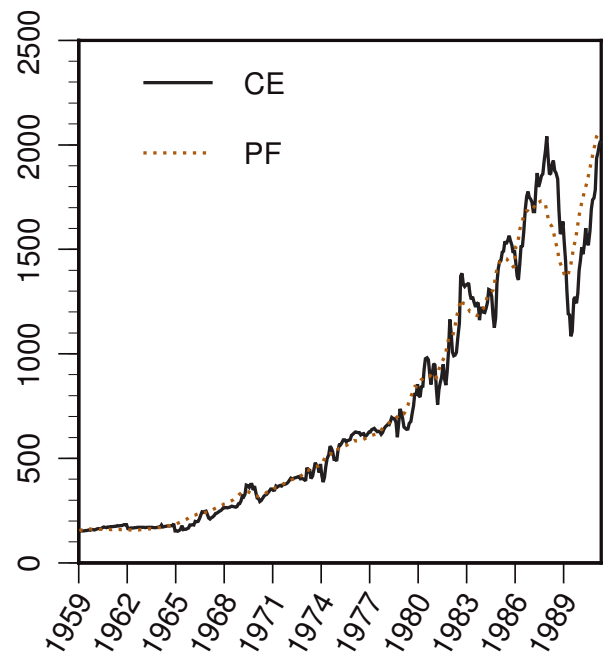

Figure 8. Economic Capital Stock of Money (M3)

Table 2

Evaluation of CE index relative to perfect foresight CSM

\begin{tabular}{lrrr}
\hline & MPE & MAPE & RMSE \\
\hline CE1 & $0.05 \%$ & $2.64 \%$ & 12.80 \\
CE2 & $0.93 \%$ & $6.41 \%$ & 85.36 \\
CE3 & $0.96 \%$ & $7.20 \%$ & 123.88 \\
\hline
\end{tabular}

\section{Conclusion}

The CSM differs significantly from the Federal Reserve's official measure of the stock of money, which confounds the present value of the investment yield of monetary assets and the true money stock. This confounding causes the official aggregates to overstate and to smooth the dynamics of the money stock. This confounding has been addressed by Barnett et al. (2005, 2008), but those papers accounted for both current and future monetary portfolio decisions. By isolating the current portfolio decision from future decisions, the CSM provides an aggregate suitable for any macroeconomic model with a variable representing currency, such as overlapping generations models with spacial separation.

Our results suggest that that the nominal user costs of monetary services can be predicted reasonably well by a martingale forecasting model and that the martingale forecasting model outperforms more sophisticated models. Moreover, a comparison of the CE to the CSM calculated under perfect foresight 
reveals that the CE closely tracks the CSM calculated under perfect foresight and that the $\mathrm{CE}$ exhibits little or no bias. Hence, I conclude that the currency equivalent index can be relied upon to be an unbiased and internally consistent measure of the CSM.

\section{References}

Bai, J., Ng, S., 2002. Determining the number of factors in approximate factor models. Econometrica 70 (1), 191-221.

Bai, J., Ng, S., January 2007. Forecasting economic time series using targeted predictors, http://www-personal.umich.edu/ ngse/papers/jointarget.pdf.

Barnett, W. A., 1991. A reply to Julio J. Rotemberg. In: Belongia, M. T. (Ed.), Monetary Policy on the 75th Anniversary of the Federal Reserve System. Proceedings of the Fourteenth Annual Economic Policy Conference of the Federal Reserve Bank of St. Louis, Kluwer, pp. 189-222. Reprinted in The Theory of Monetary Aggregation, William Barnett and Apostolos Serletis (eds.), 2000, Amsterdam: Elsevier, 296-306.

Barnett, W. A., 1995. Exact aggregation under risk. In: Barnett, W. A., Salles, M., Moulin, H., Schofield, N. (Eds.), Social Choice, Welfare and Ethics. Proceedings of the Eighth International Symposium in Economic Theory and Econometrics, Cambridge University Press, pp. 353-374. Reprinted in The Theory of Monetary Aggregation, William Barnett and Apostolos Serletis (eds.), 2000, Amsterdam: Elsevier, 195-216.

Barnett, W. A., Chae, U., Keating, J. W., July 2005. The discounted economic stock of money with VAR forecasting. Annals of Finance 2 (2), 229-258.

Barnett, W. A., Keating, J., Kelly, L. J., January 2008. Toward a bias corrected currency equivalent index.

Barnett, W. A., Liu, Y., Jensen, M., 1997. CAPM risk adjustment for exact aggregation over financial assets. Macroeconomic Dynamics 1 (2), 485-512. Reprinted in The Theory of Monetary Aggregation, William Barnett and Apostolos Serletis (eds.), 2000, Amsterdam: Elsevier, 245-273.

Blanchard, O. J., Fischer, S., 1989. Lectures on Macroeconomics. Cambridge: MIT Press.

Boivin, J., Ng, S., 2006. Are more data always better for factor analysis? Journal of Econometrics 132 (2), 169-194.

Cochrane, J. H., 2005. Asset Pricing, Revised Edition. Princeton: Princeton University Press.

Doornik, J. A., 2006. Ox-An Object Oriented Matrix Programming Language. London: Timberlake Consultants Press and Oxford: www.doornik.com.

Efron, B., Hastie, T., Johnstone, I., Tibshirani, R., 2004. Least angle regression. Annals of Statistics 32 (2), 407-499.

Elliott, G., Rothenberg, T.-J., Stock, J.-H., 1996. Efficient tests for an autoregressive unit root. Econometrica 64 (4), 813-836. 
Elliott, J. W., Baier, J. R., 1979. Econometric models and current interest rates: How well do they predict future rates? The Journal of Finance 34 (4), 975-986.

Hutt, W. H., 1963. Keynesianism - Retrospect and Prospect. Chicago: Regnery.

Pesando, J.-E., 1979. On the random walk characteristics of short- and longterm interest rates in an efficient market. Journal of Money, Credit, and Banking 11 (4), 457-466.

Rotemberg, J. J., Driscoll, J. C., Poterba, J. M., 1995. Money, output, and prices: Evidence from a new monetary aggregate. Journal of Business and Economic Statistics 13 (1), 67-83.

Sargent, T.-J., 1976. A classical macroeconometric model for the united states. Journal of Political Economy 84 (2), 207-237. 